\title{
Comparative Study of Regular and Vocational High School Students on Family Socioeconomic Status, Social Support, Self-Efficacy and Well-Being
}

\author{
Xiaoyuan Chu1,2, Zhenyu Li³, Binglin Yan4, Jing Han', Fuqiang Fan4 \\ ${ }^{1}$ School of Economics and Resource Management, Beijing Normal University, Beijing, China \\ ${ }^{2}$ Business School, The University of New South Wales, Sydney, Australia \\ ${ }^{3}$ Business School, Beijing Normal University, Beijing, China \\ ${ }^{4}$ School of Law, University of International Business and Economics, Beijing, China \\ Email: seancxy@126.com
}

Received 12 July 2015; accepted 8 August 2015; published 11 August 2015

Copyright (C) 2015 by authors and Scientific Research Publishing Inc.

This work is licensed under the Creative Commons Attribution International License (CC BY). http://creativecommons.org/licenses/by/4.0/

(c) (7) Open Access

\begin{abstract}
Based on the theoretical analysis, with first-hand data collection and using T-test method, this study analyzed the difference between regular and vocational high school students in family socioeconomic status, social support, self-efficacy and well-being to find out the underlying problems for vocational high school students and vocational education in China. We draw on the following conclusions: 1) regular high school student is significantly higher than vocational high school student in family socioeconomic status as well as in all its dimensions (father's degree of education, mother's degree of education, family annual income, father's occupation and mother's occupation); 2) regular high school student is significantly higher than vocational high school student in social support as well as in all its dimensions (family support, peer support and general support of others); 3) regular high school student is significantly higher than vocational high school student in self-efficacy; 4) regular high school student is significantly higher than vocational high school student in general well-being.
\end{abstract}

\section{Keywords}

Vocational Education, Family Socioeconomic Status, Social Support, Self-Efficacy, Well-Being

\section{Introduction}

Senior high school is not only a critical period for further education, but also a key period for psychological de-

How to cite this paper: Chu, X.Y., Li, Z.Y., Yan, B.L., Han, J. and Fan, F.Q. (2015) Comparative Study of Regular and Vocational High School Students on Family Socioeconomic Status, Social Support, Self-Efficacy and Well-Being. Open Journal of Social Sciences, 3, 61-68. http://dx.doi.org/10.4236/jss.2015.38006 
velopment. Since students are under intense study pressure and are mostly immature, they are more likely to experience psychological problems. Currently, the pressures that high school students faced with are from all aspects, especially for the vocational high school students. Vocational high school students are receiving education from school on the one hand, and are consciously or unconsciously involved in society on the other hand. Besides, in China, vocational high school is almost never the first choice for students; they are restricted by other factors such as bad at performance in studying. Consequently, some problems are found frequently for vocational high school students. As demonstrated in some researches, vocational high school students is significantly worse than the regular high school students in depression, phobia, paranoid [1]-[3]; and vocational high school students exert various kinds of psychological health problems [4]; as to learning anxiety and hypersensitivity tendency, vocational high school students are worse than regular high school students [3]. Moreover, in general a large percentage of vocational high school students come from families with relatively lower socioeconomic status in China. Researches home and abroad demonstrate that socioeconomic status is closely related to many students' problems. For instance, some research found that those who are reported by teachers to have trouble making friends are more likely to come from bad social background, such as low socioeconomic status [5]. Children in poverty are prone to be considered as attacker in peer evaluation [6] [7]; and the poorer a student's family financial status is, the more likely that poor interaction adaptability happens [8]. Students whose parents with high occupational status are more inclined to be popular in social interaction [9]. Research by Wright and others reveals that male teenagers from low socioeconomic status community are more likely to be involved in violence than those from high socioeconomic status community, and particularly may fight or be arrested or get involved with other serious criminal [10]. It is also found that low family socioeconomic status is related to poor peer acceptance [11] [12]. Qualitative research reveals that poor children experience more negative feelings than their counterparts from rich family and they think of themselves as members of "poor group”, which is a symbol for social isolation [13]. And children with low family socioeconomic status tend to be worse in self-efficacy [14].

\section{Methodology}

\subsection{Subjects of Study}

Cluster sampling methods were used for the investigation. 600 questionnaires were distributed to high school students aged 12 - 18 from a normal senior high school and a vocational senior school chosen in Beijing, with 541 questionnaires returned and 520 valid (male 226, female 294). The valid response rate is 86.67. The basic information of the sample is in Table 1.

FE is short for father's score of degree of education; ME is short for mother's score of degree of education; FAI is short for score of family annual income; the same below.

\subsection{Research Instrument}

The definitions of variables and data sources are shown in Table 2. Specific measuring tools are as follow:

Socioeconomic Status: the index of family SES is often measured by parents' occupation, degree of education and family income. With reference to previous studies, this research applied a self-designed self-reporting questionnaire which divided parents' occupation into 5 grades, parents' degree of education into 6 grades and family income into 6 grades.

Social Support: This research used social support appraisals (SS-A) scale (made by Vaux et al., and revised by (Xin, Chi, Geng, Zhao \& Wang, 2007) to measure social support. 20 items in total in this scale respectively measured family or family member support, peer support and general support of others. 0.91 is the coefficient of the whole scale, in which $0.84,0.81$ and 0.83 are respectively the coefficients of family support (7 items), peer support (7 items), general support of others ${ }^{1}$.

Self-efficacy: Chinese version of General self-efficacy scale (designed by Jerusalem et al. and translated and revised by Wang, Hu \& Liu, 2001) was used to measure self-efficacy. This scale consists of 10 items and uses Likert four points scoring, which has good reliability. Its coefficient of internal consistency Cronbach is 0.87 , test-retest reliability is $0.83(\mathrm{p}<0.001)$, split-half reliability is $0.82(\mathrm{p}<0.001)^{2}$.

${ }^{1}$ XIN Zi-Qiang, CHI Li-Ping, GENG Liu-Na, et al. Revision and Application of the Social Support Appraisal Scale. Chinese Mental Health Journal. 2007. 6: 379-381.

${ }^{2}$ WANG Caikang HU Zhongfeng LIU Yong, Evidences for Reliability and Validity of the Chinese Version of General Self Efficacy Scale, Chinese Journal of Applied Psychology, 2001, (01): 37-40. 
Table 1. Basic information of the sample.

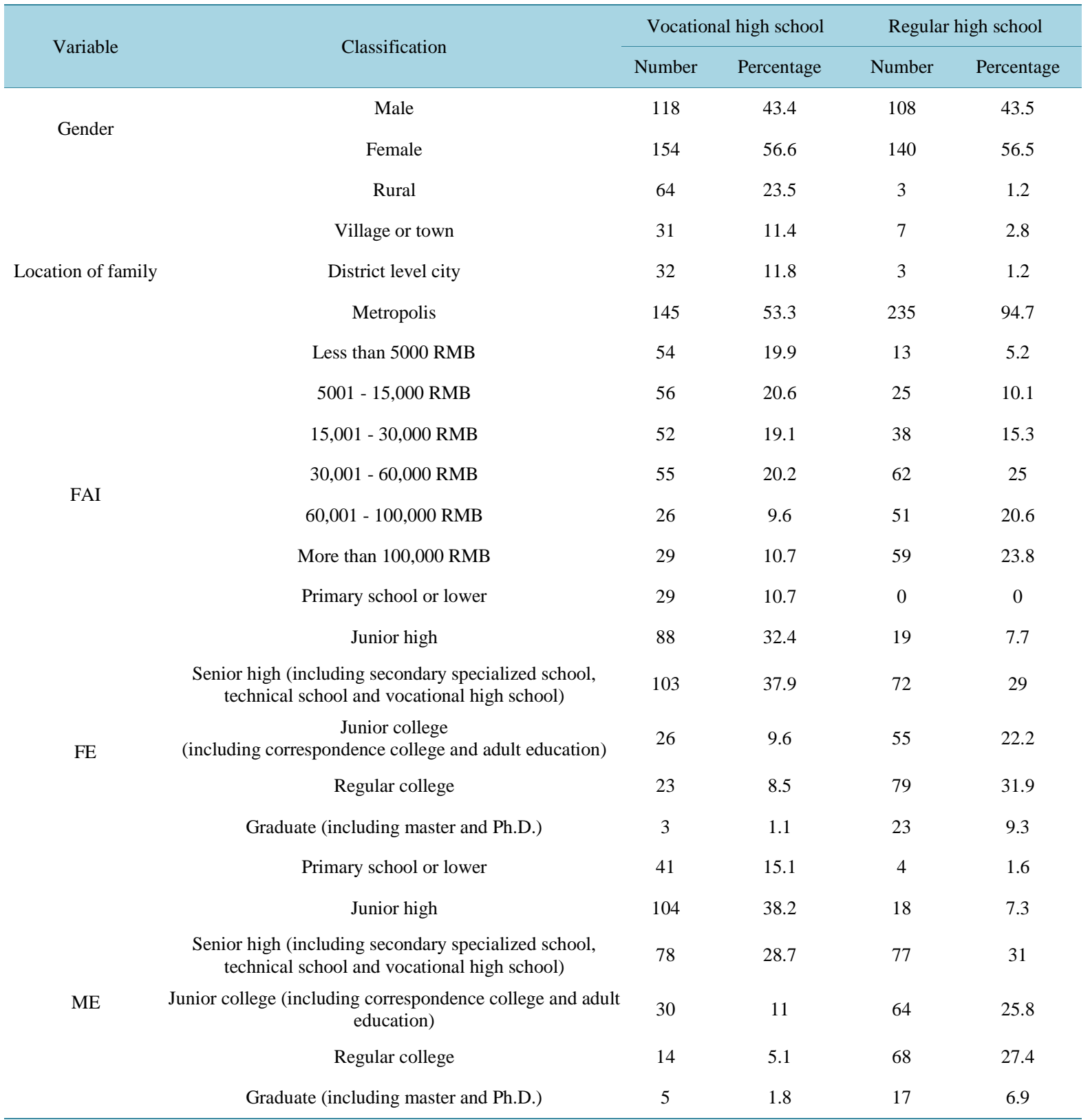

Table 2. Definitions of variables and data sources.

$\begin{array}{ccc}\text { Name } & \text { Operational definition/ } & \text { Scale } \\ \text { SE } & \text { General self-efficacy scale score } & \text { Chinese version of General self-efficacy scale } \\ \text { SES } & \text { SES }=(\mathrm{FE}+\mathrm{ME}+2 \times \mathrm{FAI}+\mathrm{FO}+\mathrm{MO}) / 6 & \text { Self-designed questionnaire } \\ \text { SS } & \mathrm{SS}=(\mathrm{FS}+\mathrm{PS}+\mathrm{GSO}) / 3 & \text { Social support appraisals scale } \\ \text { GWB } & \text { General well-being scale score } & \text { General well-being Scale }\end{array}$

Well-being: General Well-being Schedule, which is developed by American National Center for Health Statistics, is applied to evaluate happiness. This schedule consists of 33 items, and the higher the score is, the more 
intense of happiness the one felt. This survey reserved 20 items in consideration of the circumstances of Chinese teenage test-takers.

SES is short for socioeconomic status; FE is short for father's score of degree of education; ME is short for mother's score of degree of education; FAI is short for score of family annual income; FO is short for father's occupation; MO is short for mother's occupation; SS is short for score of social support; FS is short for score of family support; PS is short for score of peer support; GSO is short for General support of others. GWB is short for general well-being; the same below.

\subsection{Research Process}

The questionnaires were administrated with the whole class as a group, employing group measurement under unified instructions. And the questionnaires, with no time limitation, were collected on the spot and checked one by one with invalid ones eliminated. This research employed SPSS19.0 for statistical analysis.

\section{Results}

\subsection{Reliability of the Questionnaire}

We undertook item analysis to calculate the reliability of the questionnaire/scale for SES, social support, selfefficacy and general well-being, the coefficient Conbach $\alpha$ is in Table 3.

The data in Table 3 shows that all the four questionnaires mentioned above are all reliable with reliability above 0.8 .

\subsection{Difference in Socioeconomic Status for Regular and Vocational High School Student}

After dividing subjects into two groups in accordance with the type of schools, $\mathrm{T}$ test of socioeconomic status for regular high school student and vocational high school student was conducted. 248 students in the sample are from regular high school and 272 from vocational high school. The results are shown in Table 4.

The difference in average scores of family socioeconomic status between the two groups is 6.09, with standard error $0.463, t=13.15$. Regular high school student is significantly higher than vocational high school student in total family socioeconomic status. So is that in each dimension (father's degree of education, mother's degree of education, family annual income, father's occupation and mother's occupation).

Table 3. Cronbach's Alpha of SES, social support, self-efficacy and general well-being.

\begin{tabular}{ccc}
\hline & Cronbach's $\alpha$ & Item No. \\
SES & 0.811 & 5 \\
SS & 0.932 & 20 \\
SE & 0.896 & 10 \\
GWB & 0.805 & 20 \\
\hline
\end{tabular}

Table 4. Difference in socioeconomic status for regular and vocational high school student.

\begin{tabular}{|c|c|c|c|c|c|c|c|}
\hline Type of school & & SES & $\mathrm{FE}$ & $\mathrm{ME}$ & FAI & FO & MO \\
\hline \multirow{2}{*}{ Regular } & M & 22.6 & 4.06 & 3.91 & 4.17 & 3.25 & 3.05 \\
\hline & $\sigma$ & 5.216 & 1.135 & 1.136 & 1.472 & 1.01 & 1.025 \\
\hline \multirow{2}{*}{ Vocational } & M & 16.51 & 2.76 & 2.58 & 3.11 & 2.58 & 2.36 \\
\hline & $\sigma$ & 5.335 & 1.109 & 1.14 & 1.594 & 0.946 & 0.899 \\
\hline $\mathrm{T}$ & & 13.149 & 13.196 & 13.237 & 7.848 & 7.797 & 8.112 \\
\hline $\mathrm{P}$ & & 0.000 & 0.000 & 0.000 & 0.000 & 0.000 & 0.000 \\
\hline
\end{tabular}




\subsection{Difference in Self-Efficacy for Regular and Vocational High School Student}

After dividing subjects into two groups in accordance with the type of schools, $\mathrm{T}$ test of self-efficacy for regular high school student and vocational high school student was conducted. 248 students in the sample are from regular high school and 272 from vocational high school. The results are shown in Table 5.

The difference in average scores of self-efficacy between the two groups is 3.70 , with standard error $0.503, \mathrm{t}$ $=7.356$. Regular high school student is significantly higher than vocational high school student in self-efficacy.

\subsection{Difference in Social Support for Regular and Vocational High School Student}

After dividing subjects into two groups in accordance with the type of schools, $\mathrm{T}$ test of social support for regular high school student and vocational high school student was conducted. 248 students in the sample are from regular high school and 272 from vocational high school. The results are shown in Table 6.

The difference in average scores of social support between the two groups is 9.51, with standard error 1.19, $\mathrm{t}$ $=7.97$. Regular high school student is significantly higher than vocational high school student in social support. So is that in each dimension (family support, peer support and general support of others).

\subsection{Difference in General Well-Being for Regular and Vocational High School Student}

After dividing subjects into two groups in accordance with the type of schools, $\mathrm{T}$ test of general well-being for regular high school student and vocational high school student was conducted. 248 students in the sample are from regular high school and 272 from vocational high school. The results are shown in Table 7.

The difference in average scores of general well-being between the two groups is 2.46, with standard error 1.321, $\mathrm{t}=1$.869. Two-tailed test is marginal significant at the level of 0.05 , and one-tailed test is significant at the level of 0.05 . And regular high school student is significantly higher than vocational high school student in general well-being.

\section{Discussion}

In most developed countries, vocational education is one of the options for students to choose in consideration

Table 5. Difference in self-efficacy for regular and vocational high school student.

\begin{tabular}{cccccc}
\hline Type of school & M & $\sigma$ & SE & T & P \\
\hline Regular & 27.71 & 5.927 & 0.376 & 7.356 & 0.000 \\
Vocational & 24.00 & 5.547 & 0.336 & & \\
\hline
\end{tabular}

Table 6. Difference in social support for regular and vocational high school student.

\begin{tabular}{|c|c|c|c|c|c|}
\hline Type of school & & PS & FS & GSO & SS \\
\hline \multirow{2}{*}{ Regular } & M & 28.93 & 29.88 & 23.93 & 82.70 \\
\hline & $\sigma$ & 5.54 & 5.55 & 4.61 & 13.43 \\
\hline \multirow{4}{*}{ Vocational } & $\mathrm{M}$ & 25.56 & 26.79 & 20.8 & 73.18 \\
\hline & $\sigma$ & 5.87 & 5.64 & 4.63 & 13.70 \\
\hline & $\mathrm{T}$ & 6.70 & 6.30 & 7.69 & 7.97 \\
\hline & $\mathrm{P}$ & 0.000 & 0.000 & 0.000 & 0.000 \\
\hline
\end{tabular}

Table 7. Difference in general well-being for regular and vocational high school student.

\begin{tabular}{ccccc}
\hline Type of school & $\mathrm{M}$ & $\sigma$ & $\mathrm{SE}$ & $\mathrm{T}$ \\
\hline Regular & 82.03 & 15.243 & 0.968 & 1.869 \\
Vocational & 79.57 & 14.833 & 0.899 & 0.062 \\
\hline
\end{tabular}


of future career planning and personal development, while we still divide students mostly on the basis of their test scores into different ranks, among which vocational education is one of the lowest ranks in China. Furthermore, as discovered in this research, although academic performance is the obvious determinant for student to get vocational education or general and higher education, some other underlying factors (such as family backgrounds) also play a role in this process. It is more stunning that students from vocational high school are notonly worse at academic performance and social economic status, but also poorer in self-efficacy, social support, even in well-being than students from regular high school.

As for vocational high school student, both parents of the sample have an average education of junior high school to senior high school with an annual household income of 15,001 to 60,000RMB; while for the regular high school student, the average education their fathers received is junior college to regular college (closer to junior college) and the average education their mother received is senior high school to junior college (closer to junior college) with an annual household income of 30,001 to 100,000RMB. Generally speaking, vocational high school students are more likely to come from low-income families with parents without high education and work at the bottom of the society. This reflects, to some extent, the inequality of social resources allocation and educational opportunity in China. Children from family with higher socioeconomic status have a greater chance to be admitted in regular high school and receive higher education. On the contrary, children from family with lower socioeconomic status are more likely to receive vocational education. This phenomenon hinders social mobility, which means more difficulty for those who are born in family with lower socioeconomic status to improve their social hierarchy through education. And through in-depth interview, we find several possible explanations for this phenomenon: To begin with, degree of education is an important component of socioeconomic status. And the well-educated parents may pay more attention to children's education, and are more likely to have the knowledge of how to educate children. As a result, more often than not, they prefer to send their children to regular high school for education. Moreover, family annual income is another component of socioeconomic status. Families with higher income possess more economical and social resources. So they may spend more money (or other resources) on children's education, which in turn influences children's academic performance and further impact children's choices of school. At last, socioeconomic status also affects the expectations of children from others and themselves, which may realize in real life through Rosenthal effect. And the choice of school is one of those expectations. Finally, families with higher socioeconomic status are under less financial pressure. Hence children from families with higher socioeconomic status are less likely to choose vocational high school for the money issues and there is less chance for them to suffer from financial pressure, which would have some impact on academic performance.

Vocational high school students are more likely have lower self-efficacy than their counterparts in regular high school. Firstly, the difference in academic performance between regular and vocational high school students can be an explanation. Generally speaking, vocational high school students are worse than regular high school students academically, and as a result their academic self-esteem is generally lower than that of the regular high school students. And in China, academic performance is one of the most important parts in the social evaluations of the teenagers. Hence academic self-esteem largely affects the self-efficacy for high school students in China. Secondly, the difference in self-efficacy can be explained by the difference in family socioeconomic status. As mentioned before, regular high school students are significantly better than vocational high school students in socioeconomic status and all its dimensions. As indicated by other researches, family socioeconomic status affects children's self-efficacy. And this effect works in several ways: Firstly, some problems can be solved more easily because of the possession of resources for family with higher socioeconomic status, which in turn influence children's sense of control in general. And this sense would affect self-efficacy. Secondly, Rosenthal Effect plays a role in this place as well. Family socioeconomic status influences other's judgment of the children, which further influences self-efficacy of the children. Furthermore, parents' degree of education is one of the components in family socioeconomic status, which may influence parental method and communication style in the family, which indirectly affects self-efficacy of high school students. At last, another component of family socioeconomic status, parents' occupations have some impact on the parents' social status, which to some degree affects their children's social status. And this social status difference can also be an explanation.

Regular high school student is higher than vocational high school students in social support as well as all its dimensions. This conclusion indicates vocational high school students perceive less social support in general. This conclusion agrees with the findings of former research: less social support is related to lower socioeco- 
nomic status. Since many of vocational high school students are from poorer families, their social supports are worse than that of regular high school students who are with relatively higher socioeconomic status. And this difference can be found in family support, peer support and general support of others. Parents with lower socioeconomic status are often less educated. So they are more likely to lack of communication skills (parent-child communication skill, couples communication skill, etc.) and have less knowledge on how to provide children with family support, compared with parents with higher socioeconomic status. Furthermore, because parents with lower socioeconomic status have relatively worse jobs and lower salary, more energy and time are taken to make ends meet. Hence, it is more likely for them to not recognize and meet their children's need of family support. As a result, children from low socioeconomic status families get less support from family. Meanwhile, it is more likely for children from high socioeconomic status families to learn from past experiences on how to provide support to others. Consequently, the students in regular high school are more likely to obtain support from peers. And since interpersonal relationship is always mutual, it is more likely for these who got peer support before to provide social support to others in return. All above-mentioned experiences would construct the cognitive schema for the student, which has much influence on the perception of general support of others.

As mentioned above, the difference between regular and vocational high school students in general well-being is significant. And the score in well-being for regular high school student in average is higher than that of vocational high school student. This finding deserves more attention in future research. Vocational education is initially set up for the purpose that providing another option for the students who prefer to get some career training instead of accepting higher education, during which students' interest is supposed to be the key reason. However for most vocational high school students, academic performance is the actual reason to choose vocational education instead of regular high school and higher education in China, which is totally not for the interests and personal free choices. To make matters worse, some underlying factors have significant effect on the academic performance of students. As we found in this study, socioeconomic status determines to some extent the academic performance of students, and further influences the choice of students for further education. In China, since the beginning of imperial examination, studying has been an important pathway for students born in humble families to change their lives as well as a vital channel for social mobility. However, this pathway may be hindered by the widening of income gap between the rich and the poor in China nowadays. In another word, students with low family socioeconomic status have to work even harder to change their life through studying and education. What is more pathetic, the differences between regular and vocational high school students are not only in academic performance and family backgrounds, but also in social support, self-efficacy and well-being. In general, born in family with lower socioeconomic status may mean more possibility to have less social support, lower self-efficacy and less subjective well-being.

\section{Conclusions}

1) Regular high school student is significantly higher than vocational high school student in family socioeconomic status as well as in all its dimensions (father's degree of education, mother's degree of education, family annual income, father's occupation and mother's occupation).

2) Regular high school student is significantly higher than vocational high school student in social support as well as in all its dimensions (family support, peer support and general support of others).

3) Regular high school student is significantly higher than vocational high school student in self-efficacy.

4) Regular high school student is significantly higher than vocational high school student in general well-being.

\section{Fund}

This study was supported by China Scholarship Council (No. 201506040126).

\section{References}

[1] Xu, J. and Niu, X.Y. (2000) Psychological Health Survey for Vocational High School Student. Heilongjiang Nursing Journal, 6, 24-25.

[2] He, G. (2002) A Study on the Mental Health Level of Freshman. Journal of Changsha University, 16, 76-77.

[3] Ma, H.X. and Wang, F.L. (1994) Anxiety Survey for 282 High School Students. Theory and Practice of Education.

[4] Zhou, S.-J. (2005) Survey and the Countermeasure of the Vocational Senior Middle School Students Mentality in 
Hangzhou Region. Journal of Hetan Teachers College, 25, 208.

[5] Woodward, L.J. and Fergusson, D.M. (1999) Childhood Peer Relationship Problems and Psychosocial Adjustment in Late Adolescence. Journal of Abnormal Child Psychology, 87-104.

[6] Patterson, C.J., Kupersmidt, J.B. and Vaden, N.A. (1990) Income Level, Gender, Ethnicity, and Household Compositions as Predictors of Children's School-Based Competence. Child Development, 61, 485-494. http://dx.doi.org/10.1111/j.1467-8624.1990.tb02794.x

[7] NICHD Early Child Care Researh Network (2004) Trajectories of Physical Aggression from Toddler Hood to Middle Childhood. Monographs of SRCD, 69, Serial No. 278.

[8] Liang, Q.S. (2006) Comparative Study on Adaptability of Vocational Students with Different Economic Status. Liaoning Education Research, 26.

[9] Rao, Y.-T., Zhang, H.-X. and Li, X.-N. (2004) Impact of the Family Factors on College Students' Depression and Alienation. Psychological Development and Education, 75.

[10] Wight, R.G., Bottcello, A.L. and Aneshensel, C.S. (2006) Socioeconomic Context, Social Support, and Adolescent Mental Health: A Multilevel Investigation. Journal of Youth and Adolescence, 35, 115-126. http://dx.doi.org/10.1007/s10964-005-9009-2

[11] Dishion, T.J. (1990) The Family Ecology of Boys’ Peer Relations in Middle Childhood. Child Development, 61, 874892. http://dx.doi.org/10.2307/1130971

[12] Bolger, K.E. (1995) Psychosocial Adjustment among Children Experiencing Persistent and Intermittent Family Economic Hardship. Child Development, 66, 1107-1129. http://dx.doi.org/10.1111/j.1467-8624.1995.tb00926.x

[13] Zhang, W., Li, D.-P. and Xie, Z.-J. (2007) Low Socioeconomic Status and Child Development. Journal of South China Normal University (Social Science Edition).

[14] Han, J., Chu, X.Y., Song, H.C. and Li, Y. (2014) Social Capital, Socioeconomic Status and Self-Efficacy. Applied Economics and Finance, 1, 1-10. http://dx.doi.org/10.11114/aef.v2i1.607 